See discussions, stats, and author profiles for this publication at: https://www.researchgate.net/publication/309468891

Personal and social responsibility development: exploring the perceptions of Portuguese Youth football coaches within competitive youth sport

Article · October 2016

DOl: 10.1080/21640629.2016.1249643

\section{CITATIONS}

3

5 authors, including:

\section{Fernando Santos}

Polytechnic Institute of Porto and Viana do Castelo

18 PUBLICATIONS 18 CITATIONS

SEE PROFILE

Leonor Regueiras

University of Porto

8 PUBLICATIONS 11 CITATIONS

SEE PROFILE

Some of the authors of this publication are also working on these related projects:

Project Physical Education and PYD View project

Project Integrating Positive Youth Development in Coach Education View project
READS

100

Nuno Corte-Real

University of Porto

49 PUBLICATIONS 72 CITATIONS

SEE PROFILE

Antonio Fonseca

University of Porto

133 PUBLICATIONS 619 CITATIONS

SEE PROFILE 


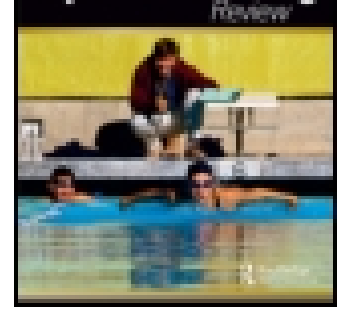

\title{
Personal and social responsibility development: exploring the perceptions of Portuguese Youth football coaches within competitive youth sport
}

\author{
Fernando Santos, Nuno Corte-Real, Leonor Regueiras, Cláudia Dias \& \\ António Fonseca
}

To cite this article: Fernando Santos, Nuno Corte-Real, Leonor Regueiras, Cláudia Dias \& António Fonseca (2016): Personal and social responsibility development: exploring the perceptions of Portuguese Youth football coaches within competitive youth sport, Sports Coaching Review, DOI: 10.1080/21640629.2016.1249643

To link to this article: http://dx.doi.org/10.1080/21640629.2016.1249643

\section{曲 Published online: 26 Oct 2016.}

Submit your article to this journal $\llbracket$

\section{Q View related articles $₫$}

View Crossmark data $\nearrow$ 


\title{
Personal and social responsibility development: exploring the perceptions of Portuguese Youth football coaches within competitive youth sport
}

\author{
Fernando Santos ${ }^{\mathrm{a}}$, Nuno Corte-Real ${ }^{\mathrm{a}}$, Leonor Regueiras ${ }^{\mathrm{b}}$, Cláudia Dias ${ }^{\mathrm{a}}$ and \\ António Fonseca ${ }^{a}$
}

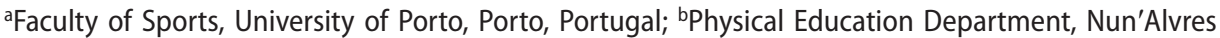
Institute, Santo Tirso, Portugal

\begin{abstract}
Youth sport is a valuable context to foster the development of personal and social responsibility (PSR). Within competitive youth sport coaches face many challenges promoting PSR while still being required to win. However, information related to the role played by coaches in PSR development within competitive youth sport is scarce and thus additional research is required. The purpose of this study was to analyse the perceptions of youth coaches on delivering, and barriers to delivering PSR in competitive youth sport. The data were collected through semi-structured interviews conducted with 17 youth coaches who coached under- 15 football teams in Portugal. A thematic analysis was performed which generated high (e.g. coaching practice) and low order categories (e.g. positive transference). The findings showed that coaches considered PSR development important in different developmental stages. The relationship between parents and coaches was identified as a key factor. Coaches experienced constraints to their intervention towards PSR development, such as challenging athlete behaviours which were resolved by implementing negative teaching strategies. Coaches also mentioned a low number of strategies to foster transference of PSR to other life domains.
\end{abstract}

\section{ARTICLE HISTORY}

Received 13 January 2016

Accepted 1 October 2016

\section{KEYWORDS}

Positive youth development; youth coaches; football; personal and social responsibility; transference

Youth have multiple needs associated with adolescence such as the need to connect with peers, belong within the school context, to search for a physically and psychologically safe environment, among other key factors that may convey positive developmental experiences (Martinek, Schilling, \& Hellison, 2006). Carroll, Ashman, Bower, and Hemingway (2013) highlighted the need for educational agents to purposefully create contextual conditions so young people can flourish. Researchers interested in comprehending youth's developmental process 
envisioned a new framework called positive youth development (PYD). This framework highlights youths' strengths instead of treating the problems experienced throughout the developmental process (Lerner, Almerigi, Theokas, \& Lerner, 2005; Seligman \& Csikszentmihalyi, 2000). Based on a positive psychology perspective, PYD states that all individuals have the potential to become successful adults in contrast to the idea that some youngsters may be a lost cause. In addition to these facts, positive psychology shifts the focus from a deficit approach to a strength-based approach highlighting the need to develop a broad range of personal and social skills which can help young people become responsible adults and positive contributors to society in the future (Lerner et al., 2005).

Intervention programmes designed to foster PYD outcomes have offered opportunities to develop youths' moral identity, teach values that enable positive peer relationships, promote the ability to overcome challenging situations and attain a sense of social justice (Lerner et al., 2005). Several intervention programmes have used different contexts to foster PYD, such as theatre (Dutton, 2001) and sport (Jung \& Wright, 2012). Thus, these type of programmes include various populations such as undergraduate students (André \& Mandigo, 2013) and at risk youth (Jung \& Wright, 2012) as well as a broad range of objectives like drug abuse prevention (Dell et al., 2013). Sport-based youth development programmes have been analysed to assess their efficacy. In fact, sport's potential to attain PYD outcomes has been recognised (Escartí, Gutiérrez, Pascual, \& Marín, 2010; FraserThomas, Côte, \& Deakin, 2005; Jung \& Wright, 2012; Martinek et al., 2006). More specifically, Fraser-Thomas et al. (2005) emphasised the importance of creating sport settings oriented towards PYD objectives, highlighted the relevance of environmental factors, and that sport should not be perceived as a space in which PYD outcomes are automatically generated (Fraser-Thomas \& Côte, 2009). In fact, there have been concerns regarding negative developmental outcomes associated with sport participation, such as violent behaviours (Roth \& Brooks-gunn, 2003). Therefore, there is a need of delivering sport programmes that aim to promote PYD outcomes through an explicit approach and develop strategies to achieve those outcomes in such a way that PYD through sport becomes a more tangible reality (Petitpas, Cornelius, Raalte, \& Jones, 2005; Vierimaa, Erickson, Côté, \& Gilbert, 2012).

A model that has guided numerous interventions conducted by teachers and coaches is the Teaching Personal and Social Responsibility Model (TPSRM) created by Hellison (2011). Personal and social responsibility (PSR) development refers to five specific competencies: respect (level one), effort (level two), autonomy (level three), leadership (level four), and transference (level five). Hellison's model describes particular means to advance from one level to the next (Hellison, 2011). The most complex and final objective of the TPSRM is to foster the transference from sport to the individuals' life. This is the core component of the TPSRM (Gordon, Thevenard, \& Hodis, 2012; Turnnidge, Côté, \& Hancock, 2014; Walsh, Ozaeta, \& Wright, 2010). This model has proven to be an important tool 
in PSR development (DeBusk \& Hellison, 1989; Escartí et al., 2010; Gordon et al., 2012). Within this model, coaches as enablers are responsible for structuring activities and creating a positive climate to equip youth with the competencies needed to become more responsible for themselves and for others. However, coaches face many challenges within PSR development. For example, the integration of PSR with performance outcomes determines the success of the intervention programme and its effects on youth's development (Petitpas et al., 2005). Therefore, it is important to investigate how these challenges are suppressed and how youth sport coaches can attain PSR outcomes (Flett, Gould, Griffes, \& Lauer, 2012). For example, Wright, Whitley, and Sabolboro (2012) implemented a girls summer camp programme based on the TPSRM called "Let's Move It!". This programme has successfully promoted PSR development, despite the fact that teachers faced several challenges and were able to solve them. These challenges consisted of experiencing difficulties in helping youth leaders use an effective leadership style coherent with the TPSRM and constantly receiving new participants during the intervention programme. Jung and Wright (2012) used the TPSRM to overcome the developmental barriers of working with at risk youth in South Korea. Problematic student behaviours and not addressing transfer explicitly were identified as challenges experienced while implementing this model.

Transferring PSR from sport to other life domains has been considered a complex endeavour (e.g. Martinek \& Lee, 2012a) and several studies within school-based projects have focused on the transference to the school environment (Armour \& Sandford, 2013; Weiss, Stuntz, Bhalla, Bolter, \& Price, 2013; Turnnidge et al., 2014; Walsh et al., 2010; Weiss et al., 2013). Weiss et al. (2013) indicated the existence of transference from the sports programme "First Tee" to other life domains such as teacher-student interaction, school exams, and conflict resolution with friends. Bobilya, Kalisch, Daniel, and Coulson (2015) also described the transference of self-confidence, self-reliance, interpersonal effectiveness, and mental strength to other life domains. Gordon et al. (2012) stated that 158 physical education teachers from New Zealand believed PSR was transferred to the school environment. Finally, Gordon and Doyle (2015) suggested the need for coaches and physical education teachers to portray transference of PSR as a top priority. These agents' commitment to fostering the transference of PSR from sport to other life domains determines the level of success achieved.

The aforementioned studies have analysed the implementation of PSR-based programmes conducted in physical education settings that do not represent mainstream youth sport programmes (Turnnidge et al., 2014; Walsh et al., 2010). In addition, most research concerning the transference of PSR objectives has been conducted in after-school programmes as competitive youth sport has not been thoroughly analysed. Researchers are unanimous in recognising the need to examine the transference of PSR to other life domains within competitive youth sport, particularly in football as a culturally relevant environment in certain settings that influences youth's beliefs and values (Armour \& Sandford, 2013; Gould, Collins, Lauer, \& Chung, 2007). Youth coaches have an important role to play in providing 
experiences that convey PSR development (Camiré, Trudel, \& Bernard, 2013), being in a privileged position to create these outcomes (Flett, Gould, Griffes, \& Lauer, 2013). As a matter of fact, competitive youth sport differs from schoolbased sport due to the fact that youth's developmental needs are the main concern of educational policies and school curriculums (Fraser-Thomas \& Côte, 2009). In this measure, school-based sport programmes and recreational settings place PSR as a priority (Gilbert \& Trudel, 2006). However, PSR development cannot be considered equally important in every sport context. Instead, competitive youth sport requires coaches to balance their motivation for the purpose of wining and attaining performance outcomes with the importance of providing developmental opportunities for athletes. Competitive youth sport places performance as the main priority and in some cases PSR development is not considered as a compatible pursuit. It is expected that athletes can learn how to transfer what they have learned in sport within PSR development to their social, personal and academic lives (Camiré, Trudel, \& Forneris, 2012). However, in some cases the need to attain performance outcomes at all cost in competitive youth sport supersedes PSR development (Camiré, 2015). Turnnidge et al. (2014) emphasises the need to explicitly develop efforts to promote PSR and raises a relevant question: How are coaches fostering the transference of PSR?

Coaches face several challenges in their intervention towards PSR development (Camiré, Trudel, \& Forneris, 2009a; Forneris, Camiré, \& Trudel, 2012). Yet, there is limited information about the determinants that guide youth coaches' interventions (e.g. overcoming youth's challenging behaviours) and regarding the importance of PSR across the developmental spectrum (e.g. sensitive developmental stages for teaching PSR) (Vella, Oades, \& Crowe, 2011). Camiré, Trudel, and Forneris (2009b) suggested that coaches should intervene alongside other agents such as parents to attain success within PSR development. For example, parents can have a negative influence on youth coaches' intervention, undermining the creation of an empowering climate (Castillo, Ramis, Cruz, \& Balaguer, 2015). Empowering climates allow young players to fulfil their needs for attaining a sense of initiative and become responsible for themselves and others (Petitpas et al., 2005). Forneris et al. (2012) indicated the importance of purposefully creating an empowering climate that considers youth's voices and provides opportunities for autonomous decision-making and curriculum ownership. In this sense, the gap between stakeholders' expectations and actual experiences can be suppressed. In addition, several researchers have advocated for understanding the key factors that determine and enable coaches' efforts towards PSR development (Camiré, Trudel, \& Forneris, 2014; Camiré et al., 2013; Erickson \& Côté, 2016; Flett et al., 2013). It is also important to analyse sport systems where competitive youth sport is growing, such as high school sport in United States of America (Pot \& Hilvoorde, 2013). In this measure, more research is also needed from non-English-speaking countries (Holt, 2016).

Coach education plays an important role in shaping youth coaches' philosophies and practices, providing tools so coaches are ready to face the challenges 
implicit to PSR development (Cushion, Armour, \& Jones, 2003). Castillo et al. (2015) suggested the need to create coach education programmes that enable coaches to develop empowering climates. Coach education courses are environments in which youth coaches can learn how to facilitate PSR (Camiré et al., 2014; Wright, Trudel, \& Culver, 2007). As stated by Vella, Crowe, and Oades (2013):

While this allows coaches of youth sports to practice with a base of theoretical knowledge, the current state of formal coach education courses does not give coaches the necessary practical and specific interpersonal competencies and may leave them unprepared to facilitate positive development for young athletes. (p. 418)

Nevertheless, relevant steps have been taken to include PSR-related content in coach education courses (Falcão, Bloom, \& Gilbert, 2012). However, there is still the need to comprehend if coaches who possess some sort of certification are actually prepared to enable PSR development (Camiré et al., 2014).

The TPSRM has been mostly used with teachers in physical education settings rather than coaches, which raises the need to examine youth coaches' intervention grounded on a PSR perspective (Gould \& Carson, 2008). In addition, researchers have analysed the role played by youth coaches in facilitating positive developmental outcomes within several sports contexts such as high school sport (Camiré et al., 2013; Gould et al., 2007), mainstream sport clubs (Vella, Oades, \& Crowe, 2013) and at risk settings (Flett et al., 2012; Whitley, Bean, \& Gould, 2011). These settings prioritise PSR development differently. In this sense, research within competitive youth sport is scarce (Gould \& Carson, 2008; Strachan, Côté, \& Deakin, 2011). Coaching in competitive settings presents innumerous challenges to youth coaches as performance is highly valued and the demand for victories and records constant (Camiré, Forneris, Trudel, \& Bernard, 2011). Coaches have to attain performance outcomes, but at the same time need to focus on youth's developmental needs. The importance of reconciling competition and PYD through sport has been highlighted in the literature as "... coaches must teach youth how life skills can be transferred and applied in settings beyond sport. Coaches must increase youth's confidence in using their skills in life situations outside of sport" (Camiré, 2015, p. 35).

Having in mind the empirical research portrayed, the purpose of this study was to analyse the perceptions of youth coaches on delivering, and barriers to delivering PSR in competitive youth sport.

\section{Method}

\section{Participants}

In this study 17 male youth football coaches involved in competitive youth sport at north of Portugal were interviewed. On average, youth coaches were 34 years old, ranging from 24 to 57 years, and had 7 years of experience working in competitive youth sport. With regard to the coaches' academic background, ten had a bachelor's degree, four high school diplomas, two master's degrees and one a 
doctoral degree. On this note, all youth coaches were certified by the Portuguese Football Federation (UEFA, 2015). A purposeful sampling technique (Silverman, 2000) was used to recruit coaches who fulfilled the followed criteria: (a) worked in competitive football clubs; (b) had a coaching certificate (UEFA approved courses) and/or a degree in sports sciences; (c) had at least one year of coaching experience in competitive youth sport (Silverman, 2000). Furthermore, coaches' teams consisted of 25, 13- to 14-year olds, who trained three times a week. Each training session was at least 60 min long.

In the under-15 football regional championship that includes more than 2000 young athletes and 25 teams the season lasts for 36 weeks. This context can be characterised as a competitive setting, due to its highly elitist and demanding nature. The teams strive to win leagues or keep playing in the same division (Gilbert \& Trudel, 2006). The season is divided in two competitive stages: one to determine who is the champion; and another to assess which team is going to be demoted.

\section{Procedure}

Before beginning the data collection, this study was approved by the ethical committee of the Faculty of Sports of the University of Porto. A technical director from the local football association was used as a key informant (Creswell, 2003) and provided a list of thirty youth coaches who fulfilled the established criteria. Then, 17 coaches were contacted via phone, debriefed about the study's objectives and regarding the extent of their participation. None of them declined to participate in this study. The confidentially and anonymity of the data were assured and all the necessary procedures taken to convey an informed consent (Creswell, 2003). Primarily, the aim was not to conduct 17 interviews as suggested by Guest, Bunce, and Johnson (2006) whereas 12 were considered to be sufficient. Nevertheless, the number of interviews conducted derived from the moment in which experiential saturation was reached, which occurred by the seventeenth interview. Experiential saturation was obtained when it was not possible to conduct further meaningful coding (Fereday \& Muir-Cochrane, 2006). A posteriori, interviews were scheduled according to the participants' availability and conducted by the first author, which used an audio device to record each interview that lasted on average $38 \mathrm{~min}$, ranging from 30 to $60 \mathrm{~min}$.

\section{Interview guide}

The interview guide was based on PYD-related research, particularly on the role played by youth coaches' in facilitating positive developmental outcomes (Camiré et al., 2012; Hellison, 2011). Prior to obtaining the final version of the semi-structured guide, two pilot interviews were conducted with coaches that presented similar features as the participants included in this study. This process was performed to refine the interview guide resulting in no major changes being 
made to the initial version. However, a PYD definition was included to guide the participants: "PYD consists of promoting positive experiences to young people so a successful integration in society can occur later in life" (Lerner et al., 2005). The interview guide was divided in four sections. Primarily, the participants provided demographic information (e.g. age, coaching experience, highest level of education, coach education certification). The remaining questions included in the interviewed guide were derived to analyse youth coaches' perceptions about the challenges experienced within PSR development, transfer from sport to other life domains and the strategies used to pursue these outcomes. The interview guide was comprised of the following questions: (a) Do you believe competitive youth sport can promote PSR development?; (b) What's your perspective on competitive youth sport's role in facilitating PSR development?; (c) Can you describe the challenges you have experienced within PSR development?; (d) Do you believe football could promote transfer of PSR to other life domains?; (e) What competencies do you believe could be transferred from football to other life domains? (f) What strategies do you use to foster transfer to other life domains? Probes were used to understand coaches' perceptions about the nature of the challenges experienced in competitive youth sport while promoting PSR (e.g. can you describe a challenging situation within PSR development?), the reasons for considering PSR development challenging (e.g. why do you find it challenging to develop PSR?), on how transfer from sport to other life domains can occur (e.g. can you provide examples of transfer to other settings?, how do you try to assess transfer?) and about the strategies used to foster transfer from sport to other life domains (e.g. which strategies do you use to develop respect for others?).

\section{Data analysis}

The interviews were transcribed verbatim by the first author and then inserted into the software NVivo10 which allowed a constant analysis of the data and facilitated its organisation. In this study, a thematic analysis was performed (Creswell, 2003), leading to the segmentation of the coaches' responses into meaning units and seven low order categories (e.g. sensitive developmental stages for coaches' intervention, challenges faced by coaches in the development of PSR). The lower order categories where then combined to form two high order categories (coaching practice, transferring PSR from sport to other life domains). For example, one meaning unit in its raw format read "I think ... I think all age groups are important, I think all age groups are important to develop this work". Minor edits were made to ensure clarity and the quote was written as "I think all age groups are important to develop this work". In the preparation process for writing the manuscript, several quotes that could describe accurately each category were selected from the participants' responses and included in a reflexive journal created by the first author. The categories were organised in a hierarchical manner and created as relationships between categories were established. The first high order 
category portrayed the factors that influenced coaches' intervention towards PSR development and the low order categories specified the challenges experienced in this domain. The second high order category described coaches' perceptions regarding competitive youth sport's potential for transferring PSR from sport to other life domains and the low order categories portrayed the existence of transfer, which competencies could be transferred and the strategies implemented by the coaches with this purpose. In addition, certain categories emerged deductively (e.g. PSR competencies transferred) as other appeared inductively (e.g. sensitive developmental stages for coaches' intervention). To assess trustworthiness and validity, several procedures were conducted. The themes were constantly reviewed by the researchers involved in this study as a reflexive journal was used to register all the changes made throughout the data analysis, which facilitated reflection. This analytical procedure also involved an external researcher who possessed a master' degree and investigated PYD through sport. This agent provided insight into the data analysis. The suggestions indicated by this external consultant (e.g. punishment and accountability were merged into one low order category) helped the research team to discuss possible changes and reach the final categories that represented the data-set. This process resulted in an agreement of $88 \%$ as researchers accepted the suggestions made by the external consultant. This is considered a satisfactory value (Murphy, Dingwall, Greatbatch, Parker, \& Watson, 1998). A negative case analysis was also used to reflect the data obtained with rigour, more specifically to portray certain cases that diverged from the general tendency and were reported in the results section (e.g. other responsibility-based competencies mentioned by coaches). On the other hand, the interviews were conducted in Portuguese which was the participants' mother language and the results presented in this paper were translated into English by the first author who possesses the necessary certification to be considered a bilingual person. This process was also checked by another bilingual person external to the project. The remaining authors who had extensive experience in qualitative research and could be considered experts reviewed all stages of the data analysis.

\section{Results}

The results are presented according to the following themes: coaching practice; PSR competencies transferred; transferring PSR from sport to other life domains; strategies used to foster transference. A numeric code was used to represent the different quotes from each of the participants in this study (e.g. C8).

\section{Coaching practice}

\section{Sensitive developmental stages for coaches' intervention}

Coaches identified adolescence as the most important stage for PSR development. The occurrence of multiple psychological and physical changes was mentioned in 
an argument to justify the need to intervene towards PSR as one coach indicated $(n=9 / 17)$ :

It is an age where they are in transition and physical maturation has its periods, motives and specific characteristics. The transition from infancy to adolescence is a more sensitive period and requires special attention. (C8)

Another coach mentioned this stage as a critical moment to foster PSR:

It is the beginning of their maturity which means they start to understand what is being more mature and responsible from this stage on, they start to really comprehend it. They become more responsible, autonomous, they go alone to the training sessions and they are more independent. Until this point, they are incapable and too dependent on their parents so they do not have the need for PSR. (C15)

At the same time, some coaches $(n=6 / 17)$ also highlighted the relevance of intervening towards PSR development throughout youth's developmental process, recognising the importance of this approach in all age groups and not only in adolescence. For example, coach 12 said: I think all age groups are important to develop this work (C12).

\section{Challenges faced by coaches in the development of PSR}

Coaches emphasised the existence of a collaborative relationship with parents as a key factor in PSR development, so both agents can work towards similar objectives. One coach referred the following:

The triangle parent, athlete and coach must forcefully work. I am clearly ready, I always work with parents. If there is a parent who is indifferent to me nothing is going to work. If I say something in a training session and the parent goes and says another at home there is not a joint effort. (C11)

On the other hand, the participants in this study identified several challenges associated with the relationship maintained with parents, specifically the fact that these agents do not continue the work conducted by coaches towards PSR in other life domains. This was perceived as a limiting factor in PSR development. One of the coaches referred to this challenge:

We lost, me and the assistant coach, a lot of time communicating with him but I think the problem was not us. We were not the ones who could not realize it but the parents. We were pulling one way and the parents another. (C14)

Some coaches also mentioned other challenges in PSR development such as parents engaging in inappropriate behaviours during competition that conflicted with their efforts to develop PSR:

It was a very aggressive team with and without the ball, but the main aggression came from the stands, which means the parents could not stop insulting the referee, our players, our staff (...) the police had to intervene and it became a very difficult game. (C10)

All the coaches mentioned the existence of complex challenges within PSR development, specially while facing athletes' challenging behaviours that interfere with the success of their intervention: 
One week ago a player in my team was warming up for some time and his motivation was zero. He behaved inappropriately before entering the game, leaving the bench and throwing the clubs 'shirt to the ground and then he just left. He thought it passed to much time before entering the game and decided he did not want to participate anymore. (C16)

Nevertheless, coaches mentioned communicating with players as strategy to solve these episodes:

I talked to him for quite some time and above everything they know I am their friend. He was sorry and apologized to the team, without me telling him to do it, because he decided it was the right thing to do. (C7)

On this notion, another coach added:

Some coaches think this is the military and they should be punished. The athlete makes a mistake we should make him a martyr, hell at him. Any athlete who does something he should be heard and we should not start yelling saying you will be punished and expelled. (C2)

Many coaches $(n=10 / 17)$ also indicated the use of negative teaching strategies such as reprehending and expelling players from football clubs to deal with athlete's challenging behaviours within PSR promotion:

After he was sorry, recognizing he was wrong, we decided as a punitive measure that he would only run for three training sessions while his colleagues were training normally. He did 15 min of running, stretched and another 15 min period until the training session was finished. In that concrete situation it was useful, because we were able to reintegrate the player. $(\mathrm{C} 17)$

\section{Transferring PSR from sport to other life domains}

\section{Positive transference}

Coaches recognised that PSR could be transferred from football to other life domains:

I think there are specific values that have to do with how players relate to each other and solve problems. All of these aspects I think kids can transfer throughout the years until they reach adulthood. Then this transfer increases. (C15)

Another coach stated the impact football has on young players' lives:

I do not have any doubts that kids who supposedly are problematic if there were not in football they would be constantly involved in complicated scenarios of exclusion, probably of crime. (C8)

At the same time, coaches described several constraints that complicate the transference of PSR from sport to other life domains. Coaches indicated being complicated to assess if transfer does take place or not as one coach stated:

Many of them do not listen to their parents so how are they going to listen to a coach? However, sometimes they can hear more easily people outside their circle that in certain cases they see as a special person (...) Nevertheless, I do not know if they transfer PSR from sport to their daily lives. I know it is not easy in their age because they are 
very susceptible and have their own life (...) if they transfer or not I do not know but we have to try ... (C3)

\section{PSR competencies transferred}

Several coaches identified respect as a responsibility-based concept that could be transferred from football to other life domains:

Players arrive there with no rules due to the environment they grow up in (...) my struggle is that they learn to live in society, respecting rules and their duties (...) by acquiring rules and behaving themselves they can transfer these aspects to their social lives, in school, with parents, peers ... (C7)

Few coaches $(n=4 / 17)$ mentioned other responsibility-based competencies that could be transferred, such as effort.

\section{Strategies to foster transference}

Punishment and accountability. Coaches mentioned using punishments and accountability as strategies to foster transference from sport to other life domains:

There is not one player that is punished for something, only if it is a serious situation. I use accountability for the whole team on a good or bad note. In the end, I try to create some sort of compromise that they will probably feel off the field. (C6)

\section{Rules}

The participants in this study also highlighted establishing rules as an important strategy to promote transference:

I am very strict in terms of rules. They know with me they cannot take it easy. I try to take them to professional football which I experienced as a player where there is a lot of discipline. (C11)

\section{Communicating with players}

Communicating with players also emerged as an important strategy:

I use a lot of metaphors and comparisons. Many times when we are doing a certain training drill I present a problem and they are not finding the solution and they just want to give up and quit. Then I ask them about school. If you cannot do an exam are you going to quit or are going to do it until the end? Sometimes we are able to reach them through the situations they live on a daily basis with friends, in school, with teachers, parents and in that way we can touch every issue that is important. (C3)

Another coach added:

We have a group meeting at least two times per year to discuss concrete problems they might have. We talk about drugs in school, sexuality (...) the negative attitudes they might have in school. (C12)

A low number of coaches $(n=3 / 17)$ indicated other strategies such as integrating opportunities to develop transference from sport to other life domains within the training sessions. 


\section{Discussion}

The purpose of this study was to analyse the perceptions of youth coaches on delivering, and barriers to delivering PSR in competitive youth sport.

Regarding the developmental stage considered as the most important, coaches indicated adolescence as a sensitive period which was considered privileged to promote PSR development. PYD-related research has supported the need to intervene throughout youth's developmental process considering the different particularities of each stage (Lerner et al., 2005). Nevertheless, some coaches did mention the relevance of teaching PSR since infancy until adulthood. It was clear that coaches felt that it was important to foster PSR development in their coaching practice while working with adolescent football players. However, these findings support the notion that coaches are not the only agents responsible for positive coaching outcomes and PSR development. Coaches' perceptions of the challenges experienced in PSR development point to the need of a collaborative relationship between parents and coaches so PSR development can be attained. In this sense, responsibility-based goals could also be used by parents.

In this sense, coaches attributed the utmost importance to maintaining a sense of coherence between their intervention towards PSR development on field and parents' guidance off field (e.g. at home). Past research corroborates the importance of parental support suggesting the need for a unified intervention while teaching PSR (Camiré et al., 2009b; Dorsch, Smith, Wilson, \& McDonough, 2015; Neely \& Holt, 2014; Taylor, Schweichler, Jorgensen, McKown, \& Teresak, 2013). In fact, Camiré et al. (2013) considered critical to create sport programmes that include moments for parents and coaches to reflect and articulate strategies devoted at promoting PYD. In this study, coaches identified certain challenges that limited their work within PSR development, specifically the lack of parental support and the inexistence of PSR development outside football clubs. These results are supported by previous research (Dorsch et al., 2015; Knight \& Holt, 2012). According to the highlighted results, it is important to adopt an holistic approach towards PSR, which means parents could be aware of their children's developmental needs, share youth coaches' philosophies and promote PSR. Future research should examine coaches and parents' perceptions on how PSR outcomes can be attained through a collaboration between both agents.

On this notion, this study aimed to shed light on the challenges faced by coaches while teaching PSR. In this sense, according to coaches' perceptions young players' challenging behaviours represented a source of complexity as several situations (e.g. disrespecting coaches) were considered difficult to solve. The participants in this study mentioned implementing negative teaching strategies (e.g. punishments, expelling players) to overcome these episodes. Flett et al. (2013) also suggested that coaches use this type of strategies to foster PYD. It is interesting to note that despite considering their players are going through a sensitive developmental stage, considered ideal to teach PSR, coaches presented difficulties articulating 
strategies used to foster PSR and struggled in promoting a positive and supportive environment. Several researchers have stressed their concerns towards the incoherence between coaching philosophies and practices (Camiré, Trudel, \& Lemyre, 2013; Forneris et al., 2012; McCallister, Blinde, \& Weiss, 2000). At the same time, coaches indicated communicating with players as an important tool. This strategy is considered by several intervention programmes based on the TPSRM serving the purpose of sensitising players to PSR goals, setting expectations and solving conflicts (DeBusk \& Hellison, 1989; Li, Wright, Rukavina, \& Pickering, 2008; Martinek et al., 2006; Wright et al., 2012). Therefore, a low number of responsibility-based strategies was mentioned to suppress the challenges experienced within PSR development. These findings raise an important issue: why youth sport coaches use these strategies in competitive youth sport? In this study, despite mentioning PSR as a priority coaches addressed emerging challenges by punishing or expelling players which could be a cause for concern. Future studies should analyse in some depth why coaches in competitive youth sport find it challenging to develop PSR. It is also important to explore the reasons for using negative teaching strategies (Flett et al., 2013).

Competitive youth sport is highly demanding and youth coaches are constantly pressured to win championships and achieve records (Camiré, 2015). In some cases, these objectives are considered incompatible with PSR development. This fact could explain the difficulties presented by this sample of coaches while articulating the strategies used to facilitate the transference of PSR from sport to other life domains. This tension between performance outcomes and PSR outcomes could be based on the fact that sports clubs' philosophies designate victories as the only top priority in competitive youth sport and youth coaches cannot change or contradict this reality (Coakley, 2016). This social-cultural forces influence how much effort do coaches commit to PSR development in their coaching practice as performance outcomes in many cases supersede other concerns. In fact, this could explain the inconsistencies between coaches' intentions and the strategies mentioned to promote PSR development. However, some researchers have corroborated the idea that PSR development can coexist with concerns towards performance outcomes, as well as highlighted the importance of creating a positive climate that includes meaningful relationships, fun and opportunities to learn PSR (Gould et al., 2007; Strachan et al., 2011). Moving forward, there is the need for research designs that examine the perspectives of all actors involved in organised youth sports, such as players, coaches, parents and officials, to extend our understanding of PSR through the medium of sport. Considering the potential influence of sociocultural forces in explicit PSR interventions, future studies should investigate why coaches coach the way they do and their coaching philosophies, which are limitations of this study.

Coaches believed PSR could be transferred from football to other life domains, particularly with regard to respect for others. Other researchers have supported the same findings (Gordon et al., 2012; Walsh et al., 2010; Weiss et al., 2013). The 
fact most coaches only considered respect as a transferable competency could be derived from the complexity of PSR development and possible difficulties in transferring respect, effort, autonomy and leadership from sport to other life domains (André \& Mandigo, 2013; Walsh, 2008). It was interesting to note that despite recognising transference as achievable coaches identified certain challenges in PSR development, specifically the difficulty of assessing its occurrence. In fact, articulating efforts with parents towards PSR development could allow a better comprehension of youth coaches' interventions and allow to assess this process.

Adding to this, coaches mentioned punishing and expelling players as negative teaching strategies used to promote transference from sport to other life domains. Communicating with players and establishing rules were also indicated as strategies used to facilitate transference (Escartí et al., 2010; Walsh et al., 2010; Weiss et al., 2013). However, several researchers have argued the need to explicitly develop strategies to foster PSR development and transfer from sport to other life domains as youth coaches could provide opportunities for athletes to envision how they can transfer the competencies learned in sport to other life domains (DeBusk \& Hellison, 1989; Petitpas et al., 2005). The coaches involved in this study were not able to provide many examples of explicitly developing PSR. An approach that does not consider PSR development and that is only focused on victories could lead to foul play situations and other negative behaviours on and off the field (Fraser-Thomas \& Côte, 2009). If coaches do not envision competitive youth sport as a valuable platform to teach PSR and facilitate transfer to other life domains through a positive climate, by establishing meaningful relationships with athletes and promoting intrinsically motivating activities (Petitpas et al., 2005) this could become a tangible reality. In addition, despite the fact all participants had a coaching certificate, coaches presented difficulties in articulating strategies coherent with the PYD through sport literature. Future studies should analyse youth coaches' perceptions about their exposure to PSR training in coach educator/accreditation courses and regarding how these environments are perceived.

This study provides insight into youth coaches' perceptions regarding PSR development in competitive youth sport. Such environments have specific characteristics as coaches face challenges associated with the need to perform and foster PSR development, which in some cases could raise constraints in helping young people become responsible citizens (Coakley, 2016). Even though the participants in this study valued PSR and football's potential in facilitating transfer to other life domains, coaches supported a "zero tolerance" approach by using negative teaching strategies. Coaches and programme administrators could understand PSR and sports development as objectives that can coexist in competitive youth sport as well as promote the competencies included, for example in Hellison's (DeBusk \& Hellison, 1989) and Petitpas's (Petitpas et al., 2005) models. More research is required to understand the nature of the coaching practice in competitive youth sport as this setting still needs to be explored (Gould \& Carson, 2008). 


\section{Conclusions}

This findings suggest that competitive youth sport presents many challenges for youth coaches while developing PSR, which generated inconsistencies between football's potential to facilitate PSR development and the strategies used to pursue these outcomes. A low number of strategies including negative teaching strategies were mentioned by the coaches to solve challenges within PSR development as well as to promote transfer to other life domains. Coaches involved in competitive youth sport should consider PSR and sports development as common pursuits as the failure to adopt positive supporting strategies could lead to the inexistence of transfer from sport settings to life. Competitive sport programmes could be designed to help coaches overcome challenges and highlight the need to achieve positive developmental outcomes. Such programmes could also include strategies for coaches to work with parents and manage a coherent and articulated response to youths' developmental needs. Coach education programmes could also provide opportunities for coaches to learn how to foster PSR outcomes and work with parents.

\section{Disclosure statement}

No potential conflict of interest was reported by the authors.

\section{References}

Armour, K., \& Sandford, R. (2013). Positive youth development through an outdoor physical activity programme: Evidence from a four-year evaluation. Educational Review, 65, 85-108.

André, M., \& Mandigo, J. (2013). Analyzing the learning of the taking personal and social responsibility model within a new physical education undergraduate degree program in $\mathrm{El}$ Salvador. The Physical Educator, 70, 107-134.

Bobilya, A., Kalisch, K., Daniel, B., \& Coulson, E. (2015). An investigation of participants' intended and actual transfer of learning following an outward bound wilderness experience. Journal of Outdoor Recreation, Education, and Leadership, 7, 93-111.

Camiré, M. (2015). Reconciling competition and positive youth development in sport. STAPS, 109, 25-39.

Camiré, M., Forneris, T., Trudel, P., \& Bernard, D. (2011). Strategies for helping coaches facilitate positive youth development through sport. Journal of Sport Psychology in Action, 2, 92-99.

Camiré, M., Trudel, P., \& Bernard, D. (2013). A case study of a high school sport program designed to teach athletes life skills and values. The Sport Psychologist, 27, 188-200.

Camiré, M., Trudel, P., \& Forneris, T. (2009a). High school athletes' perspectives on support, communication, negotiation and life skill development. Qualitative Research in Sport and Exercise, 1, 72-88.

Camiré, M., Trudel, P., \& Forneris, T. (2009b). Parents' perspectives on the practice of high school sport in a Canadian context. Qualitative Research in Sport \& Exercise, 1, 239-257.

Camiré, M., Trudel, P., \& Forneris, T. (2012). Coaching and transferring life skills: Philosophies and strategies used by model high school coaches. The Sport Psychologist, 26, 243-260. 
Camiré, M., Trudel, P., \& Forneris, T. (2014). Examining how model youth sport coaches learn to facilitate positive youth development. Physical Education and Sport Pedagogy, 19, 1-17.

Camiré, M., Trudel, P., \& Lemyre, F. (2013). Le profil d'entraîneurs en sport scolaire et leur philosophie d'entraînement [The profile and coaching philosophy of high school coaches]. PHENex, 3, 1-14.

Carroll, A., Ashman, A., Bower, J., \& Hemingway, F. (2013). Readiness for change: Case studies of young people with challenging and risky behaviours. Australian Journal of Guidance and Counselling, 23, 49-71.

Castillo, I., Ramis, Y., Cruz, J., Balaguer, I. (2015). Formación de entrenadores de fútbol base en el proyecto papa [Grassroots coaches' training in the PAPA project]. Revista de Psicologia del Deporte, 24, 131-138.

Creswell, J. (2003). Research design: Qualitative, quantitative and mixed methods approaches (2nd ed.). London: Sage.

Coakley, J. (2016). Positive youth development through sport: Myths, beliefs, and realities. In N. L. Holt (Ed.), Positive youth development through sport (2nd ed.). (pp. 21-33). London: Routledge.

Cushion, C., Armour, K., \& Jones, R. (2003). Coach education and continuing professional development: Experience and learning to coach. Quest, 55, 215-230.

DeBusk, M., \& Hellison, D. (1989). Implementing a physical education self-responsibility model for delinquency-prone youth. Journal of Teaching in Physical Education, 8, 104-112.

Dell, C., Duncan, C., DesRoches, A., Bendig, M., Steeves, M., Turner, H., ... Enns, B. (2013). Back to the basics: Identifying positive youth development as the theoretical framework for a youth drug prevention program in rural Saskatchewan, Canada amidst a program evaluation. Substance Abuse Treatment, Prevention, and Policy, 8, 1-12.

Dorsch, T., Smith, A., Wilson, S., \& McDonough, M. (2015). Parent goals and verbal sideline behavior in organized youth sport. Sport, Exercise, and Performance Psychology, 4, 19-35.

Dutton, S. (2001). Urban youth development-broadway style: Using theatre and group work as vehicles for positive youth development. Social Work With Groups, 23, 39-58.

Erickson, K., \& Côté, J. (2016). A season-long examination of the intervention tone of coachathlete interactions and athlete development in youth sport. Psychology of Sport and Exercise, $22,264-272$.

Escartí, A., Gutiérrez, M., Pascual, C., \& Marín, D. (2010). Application of Hellison's teaching personal and social responsibility model in physical education to improve self-efficacy for adolescents at risk of dropping-out of school. The Spanish journal of psychology, 13, 667-676.

Falcão, W., Bloom, G., \& Gilbert, W. (2012). Coaches' perceptions of a coach training program designed to promote youth developmental outcomes. Journal of Applied Sport Psychology, $24,429-444$.

Fereday, J., \& Muir-Cochrane, E. (2006). Demonstrating rigor using thematic analysis: A hybrid approach of inductive and deductive coding and theme development. International Journal of Qualitative Methods, 5, 2-11.

Flett, M., Gould, D., Griffes, K., \& Lauer, L. (2012). The views of more versus less experienced coaches in underserved communities. International Journal of Coaching Science, 6, 3-26.

Flett, M., Gould, D., Griffes, K., \& Lauer, L. (2013). Tough love for underserved youth: A comparison of more and less effective coaching. The Sport Psychologist, 27, 325-337.

Forneris, T., Camiré, M., \& Trudel, P. (2012). The development of life skills and values in high school sport: Is there a gap between stakeholder's expectations and perceived experiences? International Journal of Sport and Exercise Psychology, 10, 9-23.

Fraser-Thomas, J., \& Côte, J. (2009). Understanding adolescents' positive and negative developmental experiences in sport. The Sport Psychologist, 23, 3-23. 
Fraser-Thomas, Côte, J., \& Deakin, J. (2005). Youth sport programs: An avenue to foster positive youth development. Physical Education and Sport Pedagogy, 10, 19-40.

Gilbert, W., \& Trudel, P. (2006). The coach as a reflective practitioner. In R. Jones (Ed.), The sports coach as educator: Re-conceptualising sports coaching (pp. 113-129). New York, NY: Routledge.

Gordon, B., \& Doyle, S. (2015). Teaching personal and social responsibility and transfer of learning: Opportunities and challenges for teachers and coaches. Journal of Teaching in Physical Education, 34, 152-161.

Gordon, B., Thevenard, L., \& Hodis, F. (2012). A national survey of New Zealand secondary schools physical education programs implementarion of the teaching personal and social responsibility (TPSR) model. Agora para la Educación Física y el Deporte, 14, 197-212.

Gould, D., Collins, K., Lauer, L., \& Chung, Y. (2007). Coaching life skills through football: A study of award winning high school coaches. Journal of Applied Sport Psychology, 19, 16-37.

Gould, D., \& Carson, S. (2008). Life skills development through sport: Current status and future directions. International Review of Sport \& Exercise Psychology, 1, 21-58.

Guest, G., Bunce, A., \& Johnson, L. (2006). How many interviews are enough?: An experiment with data saturation and variability. Field Methods, 18, 59-82.

Hellison, D. (2011). Teaching personal and social responsability through physical activity (3rd ed.). Champaign: Human Kinetics.

Holt, N. (2016). Positive youth development through sport (2nd ed.). London: Routledge.

Jung, J., \& Wright, P. (2012). Application of Helisson's responsibility model in South Korea: A multiple case study of 'at-risk' middle school students in physical education. Agora para la Educación Física y el Deporte, 14, 140-160.

Knight, C., \& Holt, N. (2012). Recommendations for coaches on enhancing parental involvement in tennis. ITF Coaching and Sport Science Review, 20, 3-5.

Lerner, R., Almerigi, J., Theokas, C., \& Lerner, J. (2005). Positive youth development a view of the issues. The Journal of Early Adolescence, 25, 10-16.

Li, W., Wright, P. M., Rukavina, P. B., \& Pickering, M. (2008). Measuring students' perceptions of personal and social responsibility and the relationship to intrinsic motivation in urban physical education. Journal of Teaching in Physical Education, 27, 167-178.

Martinek, T., \& Lee, O. (2012). From community gyms to classrooms: A framework for valuestransfer in schools. Journal of Physical Education, Recreation and Dance, 83, 1-60.

Martinek, T., Schilling, T., \& Hellison, D. (2006). The development of compassionate and caring leadership among adolescents. Physical Education and Sport Pedagogy, 11, 141-157.

McCallister, S., Blinde, E., \& Weiss, W. (2000). Teaching values and implementing philosophies: Dilemmas of the youth sport coach. Physical Educator, 57, 35-46.

Murphy, E., Dingwall, R., Greatbatch, D., Parker, S., \& Watson, P. (1998). Criteria for assessing qualitative research. In E. Murphy, R. Dingwall, D. Greatbatch, S. Parker, \& P. Watson (Eds.), Qualitative research methods in health technology assessment: A review of the literature (pp. 163-197). Nottingham: Health Technology Assessment.

Neely, K., \& Holt, N. (2014). Parents' perspectives on the benefits of sport participation for young children. The Sport Psychologist, 28, 255-268.

Petitpas, A., Cornelius, A., Raalte, J., \& Jones, T. (2005). A framework for planning youth sport programs that foster psychosocial development. The Sport Psychologist, 19, 6-80.

Pot, N., \& Hilvoorde, I. (2013). Generalizing the effects of school sports: Comparing the cultural contexts of school sports in the Netherlands and the USA. Sport in Society, 16, 1164-1175.

Roth, J., \& Brooks-gunn, J. (2003). Youth development programs: Risk, prevention and policy. Journal of Adolescent Health, 32, 170-182.

Seligman, M. \& Csikszentmihályi, M. (2000). Positive psychology. An introduction. American Psychologist, 55, 5-14. 
Silverman, D. (2000). Doing qualitative research: A practical handbook. London: SAGE.

Strachan, L., Côté, J., \& Deakin, J. (2011). A new view: Exploring positive youth development in elite sport contexts. Qualitative Research in Sport, Exercise and Health, 3, 9-32.

Taylor, A., Schweichler, J., Jorgensen, B., McKown, E., \& Teresak, M. (2013). Parental support behaviors for children participating in community soccer programs. Sport Journal, 1, 1-7.

Turnnidge, J., Côté, J., \& Hancock, D. (2014). Positive youth development from sport to life: Explicit or implicit transfer? Quest, 66, 203-217.

UEFA. (2015). Development. Retrieved from http://www.uefa.org/football-development/index. html

Vella, S., Crowe, T., \& Oades, L. (2013). Increasing the effectiveness of formal coach education: Evidence of a parallel process. International Journal of Sports Science \& Coaching, 8, 417-430.

Vella, S., Oades, L., \& Crowe, T. (2011). The role of the coach in facilitating positive youth development: Moving from theory to practice. Journal of Applied Sport Psychology, 23, 33-48.

Vella, S., Oades, L., \& Crowe, T. (2013). The relationship between coach leadership, the coachathlete relationship, team success, and the positive developmental experiences of adolescent soccer players. Physical Education and Sport Pedagogy, 18, 549-561.

Vierimaa, M., Erickson, K., Côté, J., \& Gilbert, W. (2012). Positive youth development: A measurement framework for sport. International Journal of Sports Science \& Coaching, 7, 601-614.

Walsh, D. (2008). Helping youth in underserved communities envision possible futures: An extension of the teaching personal and social responsibility model. Research Quarterly for Exercise \& Sport, 79, 209-221.

Walsh, D., Ozaeta, J., \& Wright, P. (2010). Transference of responsibility model goals to the school environment: Exploring the impact of a coaching club program. Physical Education and Sport Pedagogy, 15, 15-28.

Weiss, M., Stuntz, C., Bhalla, J., Bolter, N., \& Price, M. (2013). 'More than a game': Impact of The First Tee life skills programme on positive youth development: Project introduction and Year 1 findings. Qualitative Research in Sport, Exercise and Health, 5, 214-244.

Whitley, M., Bean, E., \& Gould, D. (2011). On the fields of the motor city: Underserved athletes' perceptions of their coaches. Journal of Coaching Education, 4, 97-121.

Wright, T., Trudel, P., \& Culver, D. (2007). Learning how to coach: the different learning situations reported by youth ice hockey coaches. Physical Education and Sport Pedagogy, $12,27-144$.

Wright, M., Whitley, M., \& Sabolboro, G. (2012). Conducting a TPSR program for an underserved girls' summer camp. Ágora para la EF y el Deporte, 14, 5-24. 